\title{
GESTÃO DE PESSOAS: PARTICULARIDADES DE EMPRESAS FAMILIARES
}

\author{
MANAGEMENT OF PEOPLE: PARTICULARITITIES OF FAMILY FIRMS
}

\section{Tatiane Silva Tavares Maia}

\section{RESUMO}

Este artigo propõe-se a entender a problemática de empresas familiares considerando a interação entre cultura organizacional, traduzida em valores e, práticas de gestão de pessoas. Para tanto, foram estudadas três empresas familiares do Sul de Minas Gerais. As origens, a história e os aspectos contextuais marcam a vida das organizações, abrindo a perspectiva da consideração de aspectos culturais presentes em decisões e ações, considerando-se que os valores organizacionais estão presentes nessas práticas de gestão. 0 estudo com recurso à pesquisa qualitativa caracteriza-se como multicasos, com técnica de entrevista em profundidade. Constatou-se que as práticas de gestão de pessoas das empresas estudadas são marcadas por valores organizacionais que se expressam em práticas de gestão de pessoas traduzidas em recrutamento, seleção, avaliação, remuneração e treinamento. As evidências empíricas da inserção de valores nas práticas de gestão demonstram que na gestão dos funcionários, os dirigentes procuram contornar imposições e determinações da racionalização administrativa.

Palavras-chave: Empresa familiar. Gestão de pessoas. Valores.

\begin{abstract}
ABSTRATC
This article is proposed to understand the problem of family businesses considering the interaction between organizational culture, translated into values, and people management practices. To this end, family enterprises were studied three southern Minas Gerais. The origins, history and contextual aspects making a life of organizations, opening the prospect of cultural aspects of consideration in decisions and actions, considering that the organizational values are present on these management practices. The study using the qualitative characterised as multicases, with in-depth interview technique. It was noted that the people management practices of firms studied are marked by organizational values that express in people management practices into recruitment, selection, evaluation, training and remuneration. The empirical evidence of entering values in management practices show that in the management of officials, leaders seek to circumvent levies and streamlining administrative determinations.
\end{abstract}

Key-Word: Family firm. Management of people. Values. 


\section{INTRODUÇÃO}

Este artigo propõe-se a entender a problemática de empresas familiares levando em consideração: cultura organizacional, traduzida em valores e, práticas de gestão de pessoas empregadas no cotidiano dessas empresas. Parte-se da concepção de que as características culturais típicas de organizações desse tipo modelam as práticas de gestão, conferindo a elas certa particularidade em relação a outras empresas.

As empresas familiares constituem um tipo específico de empresa, em que uma família interage, assumindo funções na condução de negócios, com diversos graus de interação entre seus membros. As empresas familiares podem ser caracterizadas como sendo as maiores propulsoras do bem-estar sócio-econômico. No Brasil, um estudo identificou que mais de 99\% dos negócios são originados de empresas familiares, os quais empregam mais de $60 \%$ de toda força de trabalho disponível (LEITE, 2002). Entretanto, as particularidades verificadas neste tipo de organizações levam à necessidade de compreensão dos elementos que envolvam a problemática das empresas familiares (LAMBRECHT, 2005; BORGES et al, 2008).

A empresa familiar se destaca como um tipo de organização diferenciada devido ao envolvimento da família proprietária nos negócios e também aos aspectos da cultura organizacional. 0 envolvimento da família pode ser compreendido como um aspecto que determina a cultura peculiar desse tipo de organização, tornando-a distinta em relação a um negócio não familiar. Essa distinção, acarretada pela presença da família e de uma cultura peculiar, promove características diferenciadas às práticas de gestão de pessoas dessas empresas.

A área de gestão de pessoas é uma área que assume um papel cada vez mais de destaque nas empresas que sofrem a influência da concorrência global acirrada. Mesmo nas empresas que não possuem um departamento específico, a função de gerir pessoas não deixa de ser executada, e ganha importância para se atingir os objetivos da organização. Esforços de desenvolver as políticas e práticas de gestão de pessoas são muito pertinentes ao momento atual (WRIGHT et al., 2001). Nas empresas familiares, ganha um papel relevante devido ao envolvimento de aspectos tais como sucessão, envolvimento de parentes e profissionalização.

Acredita-se que um ponto de partida para se compreender particularidades da gestão de pessoas desse tipo de organização reside em conhecer seus valores. Cabe, então, questionar como ocorre a relação entre valores e práticas de gestão de pessoas na empresa familiar. Para tanto, pode-se partir de investigações das práticas de gestão de pessoas, enfocando os valores que as orientam e outros aspectos culturais produzidos ao longo do tempo pelas empresas objeto de estudo.

O objetivo do trabalho é, portanto, investigar as práticas de gestão de pessoas, em três empresas familiares do sul de Minas Gerais, enfocando os valores que as orientam. Para tanto, as práticas de gestão de pessoas foram caracterizadas, procedendo-se à identificação e análise dos valores presentes nessas práticas.

Este artigo encontra-se dividido, além da presente introdução, em mais quatro partes. Na segunda parte apresenta-se a fundamentação teórica em que se apóia o estudo, abordando a questão da empresa familiar, suas práticas de gestão de pessoas e a relação com elementos teóricos sobre a relação entre práticas de gestão de pessoas e valores em empresas familiares; a terceira parte comporta a metodologia; em seguida, são descritos os casos de três empresas familiares, enfocando de modo sintético, valores organizacionais que foram identificados nas 
práticas de gestão de pessoas das três empresas. Finalmente apresentam-se considerações finais.

\section{GESTÃO DE PESSOAS E VALORES EM EMPRESAS FAMILIARES}

\section{CARACTERIZANDO A EMPRESA FAMILIAR}

A literatura sobre empresas familiares tem apreendido uma grande atenção aos desafios vivenciados por este tipo de organização. Trata-se de um tipo de organização que tem sido cada vez mais estudada, considerando-se a importância desse tipo de empresas, sejam aquelas de grande porte, sejam aquelas de pequeno porte.

A empresa familiar origina-se de redes de parentesco e vínculos pessoais que, pela existência de uma base de confiança mútua, são estimuladas a desenvolver um negócio. Devido à existência dessas redes verifica-se alguma simultaneidade de papéis, ou seja, os membros da família desempenham simultaneamente papéis de parentes, proprietários e gestores (TAGIURI \& DAVIS, 1996; ECCEL, et al, 2007).

Nesse sentido, os dois sistemas que constituem esse tipo de negócio: a empresa e a família, ao revelarem suas características opostas, sendo um voltado para a razão e o outro para a emoção, as regras dos sistemas entram em confronto e os conflitos aparecem. Para isso, os participantes devem estabelecer regras de convivência entre a empresa e a família de forma participativa para que exista maior probabilidade de comprometimento entre as partes.

Constata-se que existem variados conceitos atribuídos a empresas familiares. As várias definições estão fundamentadas em diferentes fatores relacionados com a propriedade, a direção e o controle. Encontram-se conceitos que classificam como familiares apenas empresas que tenham experimentado o processo de sucessão (LODI, 1998), conceitos que considera a intenção de transferir a firma para as próximas gerações (SHARMA et al, 1997) e outros, mais amplos, que não levam em conta a concretização desse processo para classificálas (MOREIRA, 2007).

Do mesmo modo, o conceito de família na sociedade contemporânea se estendeu. Surgiu a necessidade de uma compreensão mais refinada das modalidades de família. 0 modelo teórico construído a partir da interdependência entre os ciclos da vida familiar e os ciclos de vida da empresa, mesmo contribuindo ainda para entender a mudança, a sucessão e a profissionalização das empresas familiares, carece considerar a família como instituição em constante transformação que redefine papéis, valores e significados. As diferenças geracionais precisam bem incorporadas e exploradas como uma variável importante para entender a dinâmica das empresas familiares (BARROS, 2006).

As definições de empresa familiar e a própria motivação para sua criação e desenvolvimento na família tem como pontos comuns a relação entre família, empresa e o âmbito da propriedade. Além disso, se estende para a influência dos proprietários familiares sobre a sua gestão por meio de seus valores e tradições (CAVEDON \& FERRAZ, 2003; BERTUCCI ET al, 2009). Nesse sentido é que se justifica estudar as práticas de gestão de pessoas de empresas familiares considerando a cultura e, mais especificamente, os valores que marcam tais práticas gerenciais.

\section{PRÁTICAS DE GESTÃO DE PESSOAS EM EMPRESAS FAMILIARES}


As práticas de gestão constituem elementos que dinamizam o cotidiano de organizações. As ações dos dirigentes voltam-se para diferentes setores estando diante de especificidades das decisões face ao tipo de tarefa e aos agentes organizacionais. As origens, a história e os aspectos contextuais marcam a vida das organizações, abrindo a perspectiva da consideração de aspectos culturais presentes nessas decisões e ações, próprios à cultura organizacional e à cultura nacional.

No caso de empresas familiares, esses aspectos culturais assumem características específicas, envolvendo dirigentes e demais agentes, enquanto membros de uma família proprietária e das organizações. Do mesmo modo, em termos específicos de gestão de pessoas as práticas de empresas do tipo familiar assumem particularidades em função do treinamento para sucessão, administração de conflitos, envolvimento de parentes e desenvolvimento do capital intelectual familial.

Gestores de empresas familiares, com maior ou menor ênfase de membros da família como em quaisquer tipos de empresas devem conduzir ações e atividades para o atendimento de necessidades e objetivos organizacionais, práticas de gestão que envolve o planejamento (decisão), organização, direção (liderança) e controle. Esses elementos podem compor a prática de gestão de pessoas encarregam-se do andamento das atividades de gestão de pessoas (FLEURY \& FISCHER, 1989; MORAES, 2004).

A administração de pessoas nas empresas refere-se a quatro pilares da área de recursos humanos: recrutamento, seleção, avaliação de desempenho, desenvolvimento e remuneração. É ainda, estrategicamente, responsável pelo planejamento da força de trabalho, considerado mais um fator da produção, assim como a terra e o capital. Numa perspectiva de valorização das pessoas, o foco da administração de recursos humanos também envolve a busca das melhores práticas para os funcionários (LACOMBE \& TONELLI, 2001; WRIGHT et al, 2001).

Contudo, as funções gerenciais de planejar, organizar, liderar e controlar, cunhadas por Fayol (MORAES, 2004), diante da dinâmica que o mundo empresarial está sujeito na atualidade, são consideradas - em seu conteúdo clássico - uma maneira limitada de se gerenciar, que já não é suficiente.

Em organizações empresariais do tipo familiar, a prática gerencial de pessoas concernente ao planejamento pode associar-se, em determinado momento, ao processo sucessório. Outras especificidades conferem também a esse tipo de empresa práticas de organização e direção diferenciadas. Nas empresas familiares a prática de organizar e direcionar denota particularidades associadas ao envolvimento de membros da família no trabalho cotidiano e a prática de contratação de parentes.

Mas, os elementos das práticas de gestão traduzem especificidades técnicas que podem ser flexibilizados e trazerem especificidades às práticas de gestão de qualquer tipo de empresa. Os fatores associados a essa possibilidade de flexibilização são marcados por valores organizacionais. No caso de empresas familiares, tais valores mesclam-se a valores da própria família e, desse modo, pode trazer maior influência de valores sociais.

A família é um recurso peculiar, difícil de imitar que, termina por ser fonte de vantagens e também de limitações ao desempenho da organização. Esse tipo de negócio que recebe a influência especial da família desafia a lógica estabelecida devido à complexa relação famíliaempresa, intervindo na racionalidade administrativa.

0 treinamento ganha destaque principalmente relacionado à questão da sucessão. Para 
Lambrecht (2005), a sucessão deve ser pensada como um processo de longa duração que envolve treinamento dos sucessores, e não deve ser tratada como um evento transitório e esporádico. Contudo, a problemática da empresa familiar não se restringe à sucessão, envolve questões mais amplas.

$\mathrm{Na}$ empresa familiar e na gestão de pessoas se encontra comumente o desafio de unir culturas diferentes e, muitas vezes, conflitantes seja de gerações distintas atuando em conjunto ou da atuação entre funcionários, parentes e família proprietária. A tarefa de gerenciar pessoas em qualquer empresa envolve fazer com que as pessoas trabalhem em harmonia e, esse parece ser o grande desafio da gestão de pessoas nesse tipo de empresa. 0 estilo de gestão de pessoas nas empresas familiares implica a necessidade de combinar traços de personalidade que provoquem em todos os funcionários uma sensação de envolvimento e participação, independentemente dos conflitos familiares.

Sendo assim, torna-se evidente que na empresa familiar é preciso ter forte preocupação com o melhor aproveitamento de talentos. 0 potencial intelectual dos funcionários não familiares precisa ser avaliado e aproveitado para não se perder talentos apenas pelo fato de não ser membro da família e, assim não se identificar ou ser aceito na cultura. É um processo administrativo que exige estrutura organizacional e modelo de gestão flexíveis, capazes de mudar a forma de pensar dos indivíduos, envolvendo, sobretudo, os colaboradores mais antigos (VIDIGAL, 2000; ROCHA, 2002).

A continuidade da empresa familiar fica assegurada, assim, na medida em que as normas e regras sonhadas pelos fundadores convergem com a cultura familiar para as próximas gerações. Mas, é importante o sentimento de participação dos funcionários no ambiente de trabalho que deve emergir da cultura organizacional existente, influenciada pelo estilo de trabalho da família (ABRAHAMSON \& EISENMAN, 2008).

Nesse sentido, a gestão de pessoas ajuda a direcionar estrategicamente a empresa familiar transformando o sistema de gestão da empresa. 0 gerenciamento pioneiro transforma-se gradativamente em uma administração profissional que conta com participantes pertencentes à família. Mas, no entanto, estabelece a condição de terem a qualificação necessária para a atuação em um cargo da empresa (MACÊDO, 2002; BERTUCCI et al, 2009).

A contribuição da gestão de pessoas na profissionalização da empresa familiar pode iniciar-se no processo de recrutamento e seleção e ir se estendendo por todas as áreas dando suporte a organização para criar um modelo organizacional e uma arquitetura social que gerem capital intelectual.

\section{CULTURA: VALORES NAS EMPRESAS FAMILIARES}

$\mathrm{Na}$ análise das práticas de gestão de uma empresa há que se reconhecer que em todas as organizações a cultura impregna as práticas e constitui um conjunto preciso de representações mentais, um complexo definido de saberes (SROUR, 1998).

Com efeito, cultura organizacional pode ser considerada como um conjunto de pressupostos básicos que um grupo aprendeu na medida em que resolveu seus problemas de adaptação externa e integração interna, que funcionou suficientemente bem para ser considerado válido e, portanto, para ser ensinado aos novos membros como o modo de perceber, pensar e sentir com relação a esses problemas (SCHEIN, 1984). 
Dentre os elementos da cultura, os valores se destacam, sendo considerados a essência que orienta a vida da organização (FREITAS, 1991). De certa forma, identificam o que a organização tende a adotar como procedimentos para lidar com os desafios que enfrenta.

Os valores incluem modos de comportamento, como autonomia, cooperação, cortesia, economia, humor, integridade moral (ética) e obediência (HAUGH \& MCKEE, 2004). Tratase de regras desenvolvidas pelos indivíduos para orientá-los em suas vidas. Para Motta (1997), as organizações desenvolvem alguns poucos valores que são basicamente destacados, sendo constantemente reiterados.

O estudo de valores pode, entretanto, levar em consideração a possibilidade de que valores profundos de uma organização encontram-se encobertos por discursos tradicionais que mascaram os reais valores organizacionais. Os elementos simbólicos visíveis (comportamentos aparentes dos indivíduos, processos de gestão, formas de comunicação, linguagem, os rituais organizacionais) expressam os valores básicos que orientam a vida organizacional. Assim, podem ser enfocadas as formas de organizar, bem como o significado atribuído ao trabalho, as relações de poder e as relações com o ambiente (FLEURY \& FLEURY, 1995).

Nesse sentido, abre-se a perspectiva da análise da cultura por meio de práticas organizacionais, desvendando como o grupo de pessoas que criam a organização foi aos poucos desenvolvendo formas próprias de lidar com os problemas de adaptação externa e integração interna.

$\mathrm{Na}$ perspectiva de busca de valores que orientam a vida organizacional, cabe, igualmente, enfocar as práticas de gestão manifestadas nos processos de recrutamento, seleção, treinamento, remuneração, avaliação e relações com funcionários, próprios ao cotidiano administrativo relativo à área de gestão de pessoas.

0 estudo da cultura organizacional envolve, necessariamente, a consideração de aspectos contextuais, que se inscrevem no esforço de compreensão e explicação de fatos organizacionais. Assim, o estudo de organizações empresariais familiares brasileiras envolve aspectos tais como traços culturais brasileiros, associados com valores de famílias proprietárias e de fundadores.

Algumas características da cultura nacional, presentes nos estudos de DaMatta (1983), Freyre (1966) e Holanda (1984) foram analisadas, em estudos organizacionais. Diante desse esforço, Borges de Freitas (1997), identificou cinco traços culturais brasileiros: hierarquia, personalismo, malandragem, sensualismo e aventureiro. Os traços envolvem características específicas e alguns, dentre eles, se reproduzem, notadamente, em empresas do tipo familiar.

Nessas organizações destaca-se o personalismo e a malandragem que possuem como características o paternalismo e o jeitinho brasileiro, respectivamente. Na concepção de Borges de Freitas (1997), o personalismo da sociedade brasileira se baseia em relações pessoais e na busca de afeto nas relações, sendo caracterizado pelo paternalismo, onde o superior (pai), ao mesmo tempo em que controla o subordinado e lhe dá ordens (relação econômica), também o agrada e o protege (relação pessoal).

Outro traço cultural brasileiro que se revela, especialmente, na cultura de empresas familiares refere-se a malandragem, representada pelo "jeitinho brasileiro", elemento que a caracteriza. 0 "jeitinho brasileiro" diz respeito a uma prática cordial que implica personalizar relações (MOTTA, 1997). Por configurar-se, assim, como uma relação amistosa, o jeitinho remete ao 
clima de camaradagem, comumente, estabelecido em empresas do tipo familiar. Parece representar uma estratégia de mediação que sinaliza a possibilidade de rompimento com a estrutura marcada pelo excesso de formalismo. Jeitinho usado para contornar as regras e normas e para lidar com a racionalização administrativa.

A formação cultural de empresas do tipo familiar pode ainda estar associada à figura do fundador. Sendo que a complexidade da cultura dessas empresas é atribuída ao papel dominante que o fundador ocupa em sua formação (DENISON et al., 2004).

Aliado à cultura nacional e à figura do fundador, os valores da família proprietária constituem um terceiro aspecto a ser considerado. A cultura familiar desenvolvida nessas organizações explica também as práticas de gestão (DAVEL \& SOUZA, 2004). A força da cultura dessas empresas vem, essencialmente, de valores singulares, associados aos lados emocional e afetivo, próprio da família. A vida familiar modela uma cultura permeada por referências valorativas, atributos morais e afetivos e sentimentos de solidariedade que se estendem para as relações empresariais (CAVEDON \& FERRAZ, 2003; ARONOFF, 2004)

Assim, ao estudar as práticas de gestão em empresas familiares, é possível apreender os valores nelas inseridos, revelando-se vertentes da especificidade da natureza desse tipo de empresa a partir de três aspectos que podem contribuir para sua formação cultural: traços culturais brasileiros, associados com valores de famílias proprietárias e de fundadores.

\section{PROCEDIMENTOS METODOLÓGICOS}

\section{TÉCNICAS DE PESQUISA}

A pesquisa aqui apreendida foi realizada a partir do estudo de três empresas familiares situadas no Sul do Estado de Minas Gerais. 0 estudo dos valores de empresas familiares foi feito com recurso à pesquisa qualitativa, caracterizando-se como um estudo multicasos (GODOY, 2005; YIN, 2005).

As empresas foram selecionadas em uma amostra intencional, levando-se em consideração a definição de empresa familiar. Adotou-se como critério, a conceituação que considera como familiar à organização em que a primeira e a segunda geração atuaram juntas em seu gerenciamento, mesmo que a ocorrência de interação entre fundadores e sucessores tenha ocorrido num momento passado.

A técnica principal de coleta de dados foi à entrevista em profundidade, conduzida a partir de um roteiro não estruturado, junto a fundadores, sócios, sucessores, num total de treze entrevistados, em três empresas familiares de setores distintos. No caso da empresa de materiais de construção, entrevistou-se o sócio fundador, sua irmã sócia, o gerente de vendas e o filho da sócia, membro da segunda geração que administra a loja filial e a esposa do sócio que o auxilia na gestão. Na empresa do setor automotivo foram entrevistados três irmãos sócios sucessores, o gerente do departamento de pessoal e um operário da retífica que trabalha na empresa desde a fundação. No terceiro caso, entrevistou-se o fundador, o filho sucessor e um funcionário, parente da família proprietária.

As visitas à empresa permitiram a prática de observação não participante, na perspectiva do observador atento (GODOY, 2005), sem, no entanto, utilizar-se de roteiro prévio. As entrevistas foram gravadas e transcritas para que as falas dos entrevistados fossem analisadas, a partir da técnica de análise de conteúdo (BARDIN, 1979; VERGARA, 2005). Regras de base dessa técnica foram adotadas dentro de uma proposta de análise que atendeu 
as necessidades da pesquisa. 0 procedimento analítico iniciou-se, assim, com a organização e sistematização das entrevistas. Inicialmente procurou-se organizar os relatos, identificandose passagens, em um processo de análise temática ou categorial: o desmembramento dos temas foi feito com base em aspectos da história da empresa (fundação, entrada dos filhos na empresa, sucessão) e das práticas de gestão de pessoas. Em seguida procedeu-se a uma nova leitura desses segmentos de entrevistas, agrupando-os segundo os valores neles expressos, em um processo de interpretação.

\section{OS CASOS ESTUDADOS}

Apresenta-se a seguir, uma exposição sintética sobre as empresas estudadas. Os casos tratamse de empresas familiares situadas no sul de Minas Gerais envolvendo os setores de materiais de construção, setor automotivo e setor de decorações. A organização do ramo de materiais de construção é a mais nova, têm 9 anos e atua nesse setor com uma loja na modalidade de showroom de materiais de acabamento e com um depósito para materiais de construção pesados.

Contudo, a segunda geração já está presente em sua administração. A empresa do setor automotivo é a mais antiga, com 47 anos. Essa empresa possui uma loja que comercializa peças automotivas paralelamente à oficina de conserto de motores. Atualmente é dirigida por três sócios filhos do fundador. A primeira sucessão ocorreu há oito anos. A empresa do setor de decorações possui 35 anos e vivenciou seu primeiro processo sucessório recentemente.

Atua no setor de decorações tanto interno como externo e com enfoque tanto residencial como empresarial, prestando serviços também de colocação de pisos de revestimento, cortinas e divisórias para escritório. A segunda geração administra a empresa, mas, o fundador ainda está presente.

Cabe ressaltar que, as empresas do setor de decoração e setor automotivo surgiram a partir do desejo de seus fundadores de construir um empreendimento para envolver a família. A idéia então seria introduzir os filhos nas atividades empresariais, possibilitando a geração de trabalho e renda para sustento da família proprietária.

\section{PRÁTICAS DE GESTÃO DE PESSOAS E VALORES: CASOS ESTUDADOS}

A análise das práticas de gestão de pessoas nas três empresas estudadas conduziu a identificação de um conjunto de valores em cada uma delas. Verificou-se que as empresas familiares pesquisadas são marcadas por valores organizacionais que se expressam em práticas de gestão de pessoas.

\section{PRÁTICAS DE GESTÃO DE PESSOAS: ALGUMAS PARTICULARIDADES}

Os aspectos gerenciais foram tratados com base na área funcional de gestão de recursos humanos. Cabe, então, ressaltar algumas particularidades de gestão das empresas familiares estudadas.

A empresa do setor de serviços, em seu processo de recrutamento e seleção, evita contratar jovens e parentes, posicionando-se de uma maneira menos comum, em relação às práticas de empresas familiares. Outro aspecto observado é o tempo de permanência dos candidatos em empregos anteriores e seu estado civil. Privilegia a contratação de pessoas casadas pressupondo-se maior nível de responsabilidade. Foca-se o treinamento nos vendedores, pois, há grande preocupação com a prestação de serviços. Existe diferença de remuneração devido 
ao sistema de comissão de vendas, funcionários antigos possuem mais clientes considerados "cativos", muitas vezes, mais fidelizados pelos funcionários do que pela própria empresa.

$\mathrm{Na}$ empresa do ramo de comércio parte-se de certo caráter de tradição na seleção de novos funcionários levando em conta origem familiar, fato possível dada à inserção da empresa em uma cidade de pequeno porte. Também se constata a prática de não contratação de parentes, contrariando os velhos hábitos de empresas do tipo familiar.

A empresa familiar do setor de produção recruta por meio de indicação e no círculo familiar, inclusive, abusando dessa última modalidade. Na seleção a experiência é irrelevante, pressupõe-se que o profissional experiente carrega vícios, sendo mais complexa sua adaptação na empresa. Uma de suas modalidades de treinamento refere-se a palestras de consultores. A avaliação é feita com a ajuda de funcionários "encarregados de setores", ou responsáveis pelo controle dos colegas de trabalho. Não há gerentes, parte-se da concepção de que essa diferenciação de cargos acarreta desigualdades.

\section{PRÁTICAS DE GESTÃO DE PESSOAS E VALORES}

A análise das práticas de gestão nas três empresas estudadas conduziu a identificação de um conjunto de valores em cada uma delas. Desse conjunto de valores verificados ao longo das fases das empresas, cinco dentre eles estão presentes nas práticas de gestão das três empresas: dedicação, afetividade, moralidade, camaradagem e paternalismo. Em seguida, serão comentados alguns valores e apresentados alguns relatos exemplificando como as evidências da pesquisa de campo foram empregadas para definir tais valores.

A análise das práticas de gestão de pessoas nas empresas permite afirmar que há vínculos afetivos entre dirigentes e funcionários, traduzido em vivências de crises, dificuldades e conquistas compartilhadas. Há envolvimento de famílias de funcionários antigos com aquelas de dirigentes, alguns desses funcionários sendo considerado "patrimônio" da empresa:

“... muitos funcionários antigos que a gente tem aqui é parte integrante do corpo da empresa. Igual a gente costuma brincar, têm a plaquetinha de patrimônio nas costas e realmente têm. Eles exercem um papel de guardião da empresa, então, cê vê que eles zelam pra uma coisa que é sua. Cê tem um sócio pra zelar pelo seu patrimônio, embora, eles não sejam sócios lá nos dividendos ..." (Relato do sucessor 1 da empresa de produção).

Tornou-se evidente, nos casos estudados, a predominância de relações afetivas entre os dirigentes e funcionários, ultrapassando vínculos organizacionais. Esse tipo de relação é intensa dada a presença de certos funcionários desde a fundação. No caso da empresa de serviços, esse aspecto se associa às circunstancias de sua fundação a partir da compra de uma massa falida. Há, portanto, preocupação com o emprego dos funcionários, considerando-se o empenho dos mesmos naquele momento crítico. Nessa empresa, nota-se, assim, a expressão de um sentimento de obrigação em preservar os empregos daqueles que se comprometeram nos momentos de crise e dificuldades:

“...eu não sou responsável só por mim aqui não. Eu sou responsável por 18 famílias, pelo emprego de cada um deles. Eu sinto que tenho que olhar pela sobrevivência deles. Muitos aqui estão com a gente desde o início e ajudaram muito, no começo, a alavancar a empresa..." (Relato da sócia da empresa de serviços). 
Visto de outro ângulo, o cultivo de sentimentos em relação aos membros da empresa faz parte do conjunto de valores presentes nas práticas de gestão de pessoal transmitidas pelo fundador da empresa de decorações aos seus sucessores. Percebe-se que, desde o momento que os filhos iniciaram suas atividades na organização, passaram a conviver num contexto cultural baseado em relações pessoais. Isso explica, em parte, a afetividade como base dos relacionamentos nessa organização:

"A dificuldade, pra mim, é, assim, com funcionários mais antigos, ter aquele respeito que muitos ali já tinha me pegado no colo. Eles falavam: 'ah, eu te peguei no colo'. Aí, depois, passar pra, não mandar, mas, dar aquelas ordens e ir estabelecendo uma relação patrão e empregado com eles..." (Relato de entrevista - sucessor de produção).

Os aspectos de afetividade de inserem em práticas associadas à gestão de recursos humanos. Isso se verifica no caso da empresa do setor de comércio, em que se reconhecem dificuldades de treinamento de certos funcionários para lidar com novas técnicas e máquinas modernas da retífica de motores. A esta presença da afetividade vincula-se, de forma evidente, um caráter paternalista, seja na concessão de favores, seja na transgressão da hierarquia de funcionários subalternos em relação ao gerente, calcados na relação com dirigentes proprietários. Mas isso está associado à difusão de uma idéia geral do "vestir a camisa" da empresa, tendência observada na busca de comprometimento no cargo e nos comportamentos pessoais:

"O pessoal mais antigo contribuiu muito pra empresa crescer. Alguns contribuíram até demais, mas, eu tenho funcionário aí que eu já te falei, devido à amizade eles permanecem aqui e vão chegar a aposentar. Porque o conhecimento deles parou no tempo e hoje eu não tenho como pegar um motor moderno e dar na mão deles. Eles têm que fazer só aquilo do tempo deles mesmo pra trás, eles não quiseram acompanhar..." (Relato do sucessor 2 da empresa de comércio).

Na empresa do setor de produção, onde grande parte dos empregados é parente do fundador, também se constata a incorporação de preocupações tipicamente paternalistas manifestadas em relações mais amigáveis e tolerantes. Diante delas, verificam-se dificuldades de gerenciamento de pessoal, considerando-se que a amizade e o respeito estabelecidos nos longos anos de convivência são levados em conta a todo o momento:

"O que eu analiso desses funcionários mais antigos, e até dos meus familiares, é que alguns têm uma certa acomodação. Eles assim, não vou falar que atrapalha a empresa não, mas, poderia desenvolver melhor, né?...Têm uns que não tem, assim, uma certa ambição, sabe, ... a gente, ás vezes, fica constrangido de chamar atenção sobre alguma coisa, faz uma coisa errada, ou, às vezes, perante os outros. Ah, não porque é parente ele fez isso, e tal e eu fico mal com os outros funcionários...Isso acaba até interferindo na família, é um problema de você ter ali autonomia e tudo nas mãos. Mas, aí, você fica pisando em ovos pra poder não se complicar com a família..." (Relato do sucessor da empresa de produção).

No mesmo sentido, verifica-se processos de avaliação que assumem um caráter personalizado, em detrimento das características da especialização profissional, contando tempo de casa e valorização da relação pessoal:

"...eu tive problema com pessoa mais velha aqui da empresa. Então, ele tava atrapalhando a equipe e eu fiz um remanejamento porque a gente acaba que, 
eles falam que a gente tem que trabalhar não com o coração, mas, de certa forma, pra você por uma pessoa que tá faltando pouco tempo pra aposentar $e$ você pôr na rua, não é fácil. É uma pessoa honesta e boa, então, você tenta dar uma remanejada, passa pra outra função e pôr outro no lugar. E foi o que eu fiz, né? , nesse caso...Em termos de vendas, lá costuma ter uns mais velhos que não quer fazer um curso e acha que sabe tudo. A gente tem que levar eles com muito jeito..." (Relato do sócio da empresa de serviços).

A condução da gestão nos casos estudados mantém um caráter paternalista assegurado por diferentes aspectos que se relacionam à afetividade. Apesar disso, a dedicação pode se manifestar tanto como uma norma, como uma contrapartida de empregados em relação aos dirigentes. A dedicação enquanto norma pode estar associada à ausência de concessão em relação ao horário de trabalho:

“...a gente exige muito aqui chegar no horário. Aqui dentro tem que ter $100 \%$ de atenção só no serviço. A gente não gosta que fique boicotando a empresa e trazendo atestado um atrás do outro e faltando muito. A gente tem os prazos dos serviços pra cumprir...A pessoa que quer desenvolver aqui dentro deve andar de acordo com essa conduta de comportamento que eu te falei..." (Relato do sucessor 1 e 2 da empresa comercial).

Mas a dedicação também pode ser apreendida em associação com expectativa dos dirigentes em termos de flexibilidade em relação ao horário de trabalho dos funcionários. Exige-se a dedicação de algum tempo à empresa, além daquele referente à jornada estabelecida em contrato. Após o final do expediente, espera-se que os funcionários se coloquem à disposição caso seja necessário, ao mesmo tempo em que se menciona a flexibilidade em relação a horário:

“...tem um pessoal aqui que é assim: chega mais tarde e quer sair mais cedo. Chega 15 para às 6 , tá todo mundo correndo. É bom esperar alguns minutinhos ou correr assim pra chegar no horário amanhã cedo..." (Relato do sucessor da empresa de serviços).

O contexto molda de maneira diferenciada a cultura, ao se considerar a gestão tradicional exacerbada, desde a criação das empresas fundadas em uma pequena cidade. Os aspectos afetivos, culturalmente incorporados nas práticas podem ser facilmente observados nas relações não só com funcionários, mas, com os clientes e fornecedores, sendo marcadas pelo tempo. Além do contexto, a personalidade dos fundadores, mesmo após a saída das empresas (produção e serviços), orienta as práticas de gestão.

Portanto, o conjunto de valores observados nesses casos, além de corresponder aos padrões da família proprietária, vincula-se à figura dos fundadores. Evidenciou-se, que, os pais além de transmitirem aos filhos seus conhecimentos técnicos e administrativos, repassaram valores pessoais que norteiam o estilo gerencial dos sucessores.

Verifica-se, pois, que as empresas estudadas são marcadas por valores organizacionais que se expressam em práticas de gestão de planejamento, organização direção e controle, em relação à gestão de pessoas. Alguns desses valores permanecem ao longo do tempo na vida dessas empresas, ocorrendo igualmente à expressão de novos valores, fatos associados á mudanças 
diversas e particularmente, à entrada de sucessores em trabalho conjunto com o fundador ou não.

Após o processo sucessório, já consolidado em duas empresas, os sucessores realizaram alterações nas práticas de gestão de pessoas. Mas, pode-se perceber que os sucessores resguardam ainda alguns valores que remetem à figura do fundador. A análise do conjunto de valores identificados permite algumas considerações sobre a cultura da empresa. Uma delas diz respeito ao contexto em que a cultura molda as práticas de gestão após o processo sucessório. A tendência ao uso de procedimentos técnicos foi percebida após os filhos assumirem a empresa. Novas formas de condução da gestão de pessoas vêm sendo consideradas necessárias para sobrevivência das empresas.

Nota-se por fim que, nas empresas as relações afetivas, além de presente no relacionamento com os empregados, se estendem para a dimensão comercial da organização, manifestando-se em atitudes de camaradagem em contatos com os clientes e fornecedores.

\section{CONSIDERAÇÕES FINAIS}

Nesse trabalho procurou-se compreender a relação entre práticas de gestão de pessoas e valores em empresas familiares. Para tal, buscou-se recuperar aspectos da história das empresas, caracterizar suas práticas de gestão e identificar os valores presentes nessas práticas.

As práticas de gestão adotadas pelas organizações foram caracterizadas considerando-se o planejamento, a organização, a direção e o controle de rotinas de recrutamento, seleção, treinamento, remuneração e avaliação. Por um processo de interpretação foi identificado um conjunto de valores em tais práticas nos três casos estudados.

Há evidências de que aspectos da cultura organizacional, nos casos estudados, permeiam práticas que, por vezes, fariam pouco sentido numa perspectiva administrativa. Certos procedimentos sistemáticos de gestão de pessoas que podem conduzir uma empresa à eficácia e eficiência organizacional, embora, reconhecidos nos negócios familiares estudados, por vezes, assumem uma importância menor em relação aos interesses da família e experiências pessoais cruciais do momento de fundação e consolidação da empresa.

A análise das práticas de gestão nas três empresas estudadas conduziu a identificação de um conjunto de valores em cada uma delas. Quanto ao estilo de gestão de pessoas, pode-se dizer que os dirigentes das empresas familiares estudadas no Sul de Minas Gerais, cultivam valores como dedicação, afetividade, moralidade, camaradagem e paternalismo. Proporcionam aos seus recursos humanos oportunidades de crescimento e incentivo tanto profissional como pessoal, exigindo em troca profissionalismo e comprometimento, honestidade e lealdade. Revela-se um jeitinho familiar nas relações funcionários e membros da família.

Ao contratarem pessoas para o quadro de trabalho, não levam em consideração a apenas a competência pessoal, buscam a lealdade e a confiança. Apresentam estilo de liderança mais voltado para as pessoas do que para as tarefas, porém os dirigentes são muito orientados para o poder, com tendência a centralização. Por outro lado, ações paternalistas, com ênfase em relações afetivas suavizam as relações de poder.

O conjunto de valores presentes nas práticas de gestão das três empresas estudadas permite aprofundar-se na busca da compreensão sobre a natureza da empresa familiar. Tais valores podem ser interpretados como partes de um conjunto sistêmico, ao se manifestarem de modo 
inter-relacionado ao longo da história de cada empresa contribuindo para o formato singular de seu sistema de gestão de pessoas.

Cabe ressaltar que, este estudo, baseado no relato de dirigentes de três empresas familiares, não pode ser generalizado. 0 trabalho apresenta evidências de práticas características das empresas dos ramos de atividades distintos e de pequeno e médio porte. Sendo assim, cabe ainda mencionar que as limitações do trabalho se referem a essa reduzida quantidade de empresas estudadas. Sugere-se então, novos estudos que contemplem ampliação quantitativa de empresas a fim de que se possa contribuir para o entendimento da dinâmica de gestão desse tipo de empresa, bem como com a tipificação de suas práticas de gestão de pessoas particulares.

As empresas familiares encontram na família e no fundador uma instância produtora de valores. Nesse tipo de organização, a família constitui um núcleo constituído e constituinte imbricado à operação empresarial em um setor econômico. Diante dessas evidências, o aprofundamento em novos estudos sobre valores em empresas familiares pode indicar particularidades de sua gestão em diferentes setores empresariais, ensejando reflexões sobre as práticas de gestão, seja no sentido de construção de novas práticas ou aprimoramento, no sentido da eficiência e da efetividade de empresas familiares brasileiras.

\section{REFERÊNCIAS BIBLIOGRÁFICAS}

ABRAHAMSON, E.; EISENMAN, M. Employee-management Techniques: Transient Fads or Trending Fashions? Administrative Science Quarterly, v.53, n. 3, p 719-744, Dec,2008.

ARONOFF, C. Self-perpetuation family organizational built on values: necessary condition for long-term family business survival. Family Business Review, v.17, n.1, p.55-59, Mar. 2004.

BARDIN, L. Análise de conteúdo. Lisboa, Edições Setenta, 1979.

BARROS, M. L. de. Família e Gerações. Rio de Janeiro: FGV Editora, 2006.

BERTUCCI, J. L. de O. Mecanismos de governança e processos de sucessão: um estudo sobre a influência dos elementos da governança corporativa na orientação do processo sucessório em uma empresa familiar. Revista Brasileira de Gestão de Negócios, São Paulo, v. 11, n.31, p. 152-167, abr/jun. 2009.

BORGES, A. F.; LIMA, J. B. de; TAVARES, T. S. Rede de Empresas Familiares e Capital Familial. In: EGEPE, 8, 2008, São Paulo. Anais... São Paulo, 2008.

BORGES DE FREITAS, A. Traços brasileiros para uma análise organizacional. In: MOTTA, F. C. P.; CALDAS, M. P. Cultura organizacional e cultura brasileira. São Paulo: Atlas, 1997.

CAVEDON, N.R. ; FERRAZ, O. L. Os diferentes modelos de família e empresa familiar e seus respectivos valores: um olhar sobre as empresas comerciais em Porto Alegre. Organização \& Sociedade, Salvador, v.10, n.27, maio/ago.2003.

DAMATTA, R. Carnavais, malandros e heróis: para uma sociologia do dilema brasileiro. Rio de Janeiro: Zahar, 1983. 
DAVEL, E.; SOUZA, J. Aprendizado e formação continuada em organizações familiares e intensivas em conhecimento: a força das relações de parentesco por consideração. In: ENEO, 4, 2004, Curitiba Anais... Curitiba: ENEO, 2004. (CD-ROM)

DENISON, D.; LIEF, C.; WARD, J.L. Culture in family-owned enterprises: recognizing and leveraging unique strengths. Family Business Review, v. 17, n. 1, p.61-72, mar, 2004.

ECCEL, C. S.; CAVEDON, N.R. ; CRAIDE, A. A empresa familiar Cachorro Quente do Rosário: entre a antropologia e a administração. Organização \& Sociedade, Salvador, v.14, n.25, maio/ago. 2007.

FLEURY, A.; FLEURY, M. T. L. Aprendizagem e inovação organizacional: as experiências de Japão, Coréia e Brasil. São Paulo, Atlas, 1995.

FLEURY, M. T. L.; FISCHER. R. M. (Orgs) Cultura e poder nas organizações. São Paulo: Atlas, 1989.

FREITAS, M. E. Cultura organizacional: formação, tipologias e impacto. São Paulo: Markron, 1991.

FREYRE, G. Casa grande e senzala. 13. ed. Rio de Janeiro: José Olympio, 1966. 330p.

GODOY, A.S. Estudo de caso qualitativo. In: GODOI, C.K.; BANDEIRA-DE-MELLO, R.; SILVA, A.B. da (Org.) Pesquisa qualitativa em estudos organizacionais: paradigmas, estratégias e métodos. São Paulo: Saraiva, 2006.

HAUGH, H.; MCKEE, L. The cultural paradigm of the smaller firm. Journal of Small Business Management, v. 42. n. 4, p 377-394, 2004.

HOLLANDA, S. B. Raízes do Brasil. 17. ed. Rio de Janeiro: José Olympio, 1984. 155p.

LACOMBE, B. M. B.; TONELLI, M. J. 0 discurso e a prática: o que nos dizem os especialistas e o que nos mostram as práticas das empresas sobre os modelos de gestão de recursos humanos. Revista de Administração Contemporânea, Rio de Janeiro, v. 5, n. 2, Maio/Ago. 2001.

LAMBRECHT, J. Multigenerational transition in family business: a new explanatory model. Family Business Review, San Francisco, v.18, n.4, p. 267-282, Dec. 2005.

LEITE, R. C. As técnicas modernas de gestão de empresas familiares. In: GRZYBOVSKI, D.; TEDESCO, J. C. (Orgs). Empresa familiar: tendências e racionalidades em conflitos. 3a ed. Passo Fundo: UPF, 2002.

LODI, J. B. A empresa familiar. 5a ed. São Paulo: Pioneira, 1998.

MACÊDO, K. B. Cultura, poder e decisão na organização familiar brasileira. Revista de Administração Eletrônica da FGV, São Paulo, v.35, n.3, p.20-29, maio/jun. 2002.

MOREIRA Jr., A. L., NETO, A. de B. Empresa familiar. São Paulo: Saraiva, 2007.

MORAES, A. M. P. de. Introdução à Administração. 3. ed. São Paulo: Printice Hall, 2004.

MOTTA, F. C. P. Cultura e organizações no Brasil. In: MOTTA, F. C. P.; CALDAS, M. P. Cultura organizacional e cultura brasileira. São Paulo: Atlas, 1997. 
ROCHA, C. H. M. da. Profissionalização x modernização: um estudo de caso de uma empresa familiar do setor têxtil. In: ENCONTRO NACIONAL DA ANPAD, 26, 2002, Salvador. Anais... Salvador: ANPAD, 2002. (CD-ROM)

SCHEIN, E. Coming a new awareness of organizational culture. Sloan Management Review, Cambrigde, v.10, n.3, p 36-48, 1984.

SHARMA, P.; CHRISMAN, J. J.; CHUA, J. H. Strategic management of the family business: past research and future challenges. Family Business Review, v. 10, n.1, p.1-35, 1997.

SROUR, R. H. Poder, cultura e ética nas organizações. Rio de Janeiro: Campus, 1998.

TAGIURI, R.; DAVIS, J. Bivalent attributes of the family firms. Family Business Review, v. 9, n. 2, p. 199-209, 1996.

VERGARA, S. C. Métodos de pesquisa em Administração. 1 ed. São Paulo: Atlas, 2005.

VIDIGAL, A. C. A sobrevivência da empresa familiar no Brasil. Revista de Administração da USP. São Paulo, v. 35, n. 2, p. 66-71, abr/jun, 2000.

WRIGHT, P. M.; McMAHAN, G. C.; SNELL, S. A.; GEHART, B. Comparing line and HR executives' perceptions of HR effectiveness: services, roles and contributions. Human Resource Management, vol. 40, n. 2, p. 111-123, Summer 2001.

YIN, R. K. Estudo de caso: planejamento e métodos. 3. ed. Porto Alegre: Bookman, 2005. 